\title{
Response of C57BI/6 mice to a carbohydrate-free diet
}

Saihan Borghjid ${ }^{1,2^{*}}$ and Richard David Feinman ${ }^{2}$

\begin{abstract}
High fat feeding in rodents generally leads to obesity and insulin resistance whereas in humans this is only seen if dietary carbohydrate is also high, the result of the anabolic effect of poor regulation of glucose and insulin. A previous study of C57BI/6 mice (Kennedy AR, et al.: Am J Physiol Endocrinol Metab (2007) 262 E1724-1739) appeared to show the kind of beneficial effects of calorie restriction that is seen in humans but that diet was unusually low in protein (5\%). In the current study, we tested a zero-carbohydrate diet that had a higher protein content (20\%). Mice on the zero-carbohydrate diet, despite similar caloric intake, consistently gained more weight than animals consuming standard chow, attaining a dramatic difference by week $16(46.1 \pm 1.38 \mathrm{~g}$ vs. $30.4 \pm 1.00 \mathrm{~g}$ for the chow group). Consistent with the obese phenotype, experimental mice had fatty livers and hearts as well as large fat deposits in the abdomino-pelvic cavity, and showed impaired glucose clearance after intraperitoneal injection. In sum, the response of mice to a carbohydrate-free diet was greater weight gain and metabolic disruptions in distinction to the response in humans where low carbohydrate diets cause greater weight loss than isocaloric controls. The results suggest that rodent models of obesity may be most valuable in the understanding of how metabolic mechanisms can work in ways different from the effect in humans.
\end{abstract}

\section{Introduction}

The high fat-fed mouse is a widely investigated model of obesity, insulin-resistance and susceptibility to diabetes. The C57Bl/6 strain, in particular, when subjected to high dietary fat, shows increased consumption, increased efficiency of fat storage (weight gained/calorie) and becomes insulin resistant [1-4]. As a model of human obesity and insulin resistance, however, it suffers from the severe, if under-emphasized, limitation that high-fat diets do not generally cause these conditions in humans unless the diets are also high in carbohydrate. In fact, carbohydrate-restricted diets (CRDs), even with high fat, are the most effective therapy for diabetes and metabolic syndrome; the greater the replacement of carbohydrate with fat, the more effective the improvement (reviews: [5-11]). In humans, it is low-carbohydrate diets that most often demonstrate energy inefficiency [12] with respect to lipogenesis and no diet is better for weight loss although macronutrient effects on energy efficiency remain somewhat controversial.

\footnotetext{
* Correspondence: sborghjid@molloy.edu

${ }^{1}$ Department of Biology, Molloy College, Rockville Centre, NY 11571, USA

${ }^{2}$ Department of Cell Biology, SUNY Downstate Medical Center, Brooklyn, NY 11203, USA
}

(c) 2012 Borghiid and Feinman; licensee BioMed Central Ltd. This is an Open Access article distributed under the terms of the Creative Commons Attribution License (http://creativecommons.org/licenses/by/2.0), which permits unrestricted use, distribution, and reproduction in any medium, provided the original work is properly cited. directly through insulin and other hormones, has a catalytic role in controlling other metabolites [10,13]. According to this principle, the observed effect of high fat diets in mice would have to be explained by the presence of sufficient dietary carbohydrate or endogenous insulin to maintain the anabolic state. An influential paper that studied C57BL/6 mice under conditions of zero carbohydrate [14] seemed to bear this out.

Kennedy, et al. [14] studied $\mathrm{C} 57 \mathrm{Bl} / 6$ mice on a high fat, ketogenic diet (KD) and showed that they displayed all the characteristics of humans on a low-carbohydrate diet: weight loss without caloric restriction, increased energy expenditure, improved glucose tolerance, and lowered serum insulin and leptin levels. The KD in Kennedy, et al.. was 95\% energy derived from fat and 5\% from protein. Such a diet is rather extreme compared to a diet that might be consumed by a human even in an experimental setting: first, 5\% energy from protein is very low and second, whereas there is no dietary requirement for carbohydrate, in humans, the effects attributed to the unique metabolic state associated with carbohydrate restriction have not generally required such an extreme fat/protein ratio. On the other hand, it 
seemed possible that, because of the small brain size and therefore limited requirements for glucose, very low carbohydrate would be necessary to reproduce in a rodent model the effect of CRDs seen in humans. We have confirmed, in work to be published elsewhere, that moderate lowering of carbohydrate had little effect on mice. We therefore tried to repeat Kennedy's experiment at more traditional levels of protein while maintaining zero carbohydrate. To our surprise, we observed the phenotype usually associated with the high fat-fed-mouse model. Animals became obese and insulin-resistant and gained substantially more weight per calorie than mice fed normal chow. We describe here the results of these experiments. The outcomes suggest that the results found by Kennedy, et al. [14] were a consequence of the low levels of dietary protein, possibly to the point of protein deprivation.

\section{Material and methods Animals}

Six-week old male C57Bl/6 mice (The Jackson Laboratory, Maine) were housed individually at $22^{\circ} \mathrm{C}$ on a 12 hour light-dark cycle. Animals were allowed ad libitum access to food, except when fasting overnight as described later. Water was available to the animals at all times. Applicable institutional and governmental regulations concerning the ethical use of animals were followed. All procedures were approved by State University of New York Downstate Medical Center Animal Care and Use Committee.

\section{Diets and diet trial}

Twenty-four six-week-old male $\mathrm{C} 57 \mathrm{Bl} / 6$ mice were acclimated to the laboratory conditions while consuming ad libitum standard chow (Normal Chow \#5001, LabDiet) until they were nine weeks old; at ten weeks, mice are generally considered adult. They were then randomly assigned to two groups and were fed $a d$ lib on either 1) a zero-carbohydrate, ketogenic diet (Zero-CHO Group, $\mathrm{n}=12$ ), or 2) continuation of the standard chow diet (Chow Group, $\mathrm{n}=11$ ). The diet compositions were as follows:

Chow Group: Normal Chow \#5001, LabDiet (http:// www.labdiet.com/); $3.36 \mathrm{kcal} / \mathrm{gm}$ with \% energy $\mathrm{CHO}$ fat:protein $=58: 13.5: 28.5$.

Zero-CHO Group: Bio-Serv Inc. (http://www.bio-serv. $\mathrm{com} /$ ); $6.1 \mathrm{kcal} / \mathrm{gm}$. The macronutrient composition: \% energy CHO:fat:protein $=0: 80: 20$. This ketogenic diet was supplemented with vitamin mix and mineral mix that is complete in micronutrients. The fat composition was Lard $(401.0 \mathrm{~g} / \mathrm{kg})$ and Butter $(142.5 \mathrm{~g} / \mathrm{kg})$.
The above diets were maintained over a sixteen-week trial period. During the trial period, body weights and ad libitum food intake were measured twice weekly. The food intake measurements were corrected for spillage. Physical activity was not monitored but by inspection, as expected, was reduced as animals got fatter.

\section{Glucose tolerance tests}

At the twelfth week of the trial period, all twenty-three mice were fasted overnight and were injected with glucose (2 gram $/ \mathrm{Kg}$ body weight) intraperitoneally. Tail blood was collected at $0,15,30,60,120$, and $180 \mathrm{~min}$. Blood glucose concentrations were measured using a glucometer (Elite, Bayer).

\section{Tissue samples}

Retro-orbital Bleeding: standard heparinized microhematocrit capillary tubes were used for blood collection under anesthesia. The blood was withdrawn after overnight fasting, and the amount of blood withdrawn was no more than $1 \%$ of the animal's body weight (e.g., $0.3 \mathrm{ml}$ from a $30 \mathrm{gm}$ adult mouse).

Terminal Bleeding and Necropsy: after overnight fasting, mice were asphyxiated to unconsciousness using $\mathrm{CO}_{2}$ and blood was withdrawn by cardiac puncture. Tissues (brain, heart, liver, skeletal muscle and fat) were collected and snap frozen in liquid nitrogen before storage at $-80^{\circ} \mathrm{C}$.

Blood serum from retro-orbital bleeding and terminal bleeding was separated by centrifugation at $5000 \mathrm{rpm}$ for $20 \mathrm{~min}$ and was stored at $-80^{\circ} \mathrm{C}$.

\section{Enzyme-linked immunoSorbent assay}

Fasting mouse serum was analyzed using EnzymeLinked ImmunoSorbent Assay (ELISA). The quantitative determination of serum leptin was done using Mouse Leptin ELISA Kit (Cat \#90030, Crystal Chem Inc., IL).

\section{Statistical analysis}

Data are presented as means \pm standard error. Statistical significance between groups was assessed by 1 ) unpaired Student t-Test; 2) one-way ANOVA and StudentNewman-Keuls post hoc analysis; 3) two-way ANOVA. Statistical significance was taken as $\mathrm{P}<0.05$.

\section{Results}

\section{Food intake and body weight}

In the first week of the trial period, mice introduced to the zero carbohydrate diet (Zero-CHO group; \% CHO: fat:protein $=0: 80: 20$ ) consumed more calories than mice on the standard chow diet (Chow group; \% CHO:fat:protein $=58: 13.5: 28.5$ ). In this period, the Zero- $\mathrm{CHO}$ group consumed $105 \mathrm{Kcal}$ compared to $94 \mathrm{Kcal}$ for the Chow group. Over the course of four weeks, differences in the 
caloric intake of the two groups were minimized and, from week four onward, mice in the Zero-CHO group and Chow group consumed roughly the same total calories weekly $(\mathrm{P}=0.38)$. This pattern of food intake continued throughout the diet trial, which lasted sixteen weeks (Inset to Figure 1).

The mean body weights for each group are shown in Figure 1. Despite the similarity in caloric intake, mice on the Zero-CHO diet consistently gained more weight than mice on standard chow throughout the sixteenweek trial period $(\mathrm{P}<0.0001)$. By week 16 , this led to dramatically heavier body weights for mice consuming the Zero-CHO diet $(46.1 \pm 1.38 \mathrm{~g})$ compared to only $30.4 \pm 1.00 \mathrm{~g}$ for the Chow group. Consistent with the obese phenotype, mice on Zero-CHO diet had fatty livers and hearts, and large amounts of fat deposition in the abdomino-pelvic cavity (data not shown).

\section{Impaired glucose clearance}

Glucose tolerance tests revealed impaired glucose clearance in mice fed Zero-CHO diet (Figure 2). Zero-CHO mice had significantly higher fasting glucose levels compared to the Chow fed group at week 12 (Zero-CHO group $138.9 \pm 6.62 \mathrm{mg} / \mathrm{dL}$ vs. Chow group $107.1 \pm 4.30 \mathrm{mg} / \mathrm{dL}$; $\mathrm{P}<0.0009$ ). Zero-CHO mice showed significantly higher levels of blood glucose at all time points compared to the Chow group following intraperitoneal glucose injection $(\mathrm{P}=0.02)$. Three hours after glucose injection, Zero-CHO group blood glucose was $91.4 \pm 22.95 \mathrm{mg} / \mathrm{dL}$ higher than baseline (0 time), more than two-fold increase over the increase of the Chow group $(43.8 \pm 12.20 \mathrm{mg} / \mathrm{dL})$.

\section{Leptin}

Fasting blood leptin levels of male $\mathrm{C} 57 \mathrm{Bl} / 6$ mice fed the Zero-CHO and standard Chow diets were measured in a separate study shown in Figure 3. The blood leptin concentration closely correlated with individual mouse's body weight $(\mathrm{R}=0.93)$. A close correlation between Zero-CHO diet induced obesity and elevation of blood leptin levels is seen in the fact that all of the Zero-CHO mice gained more weight and exhibited higher fasting

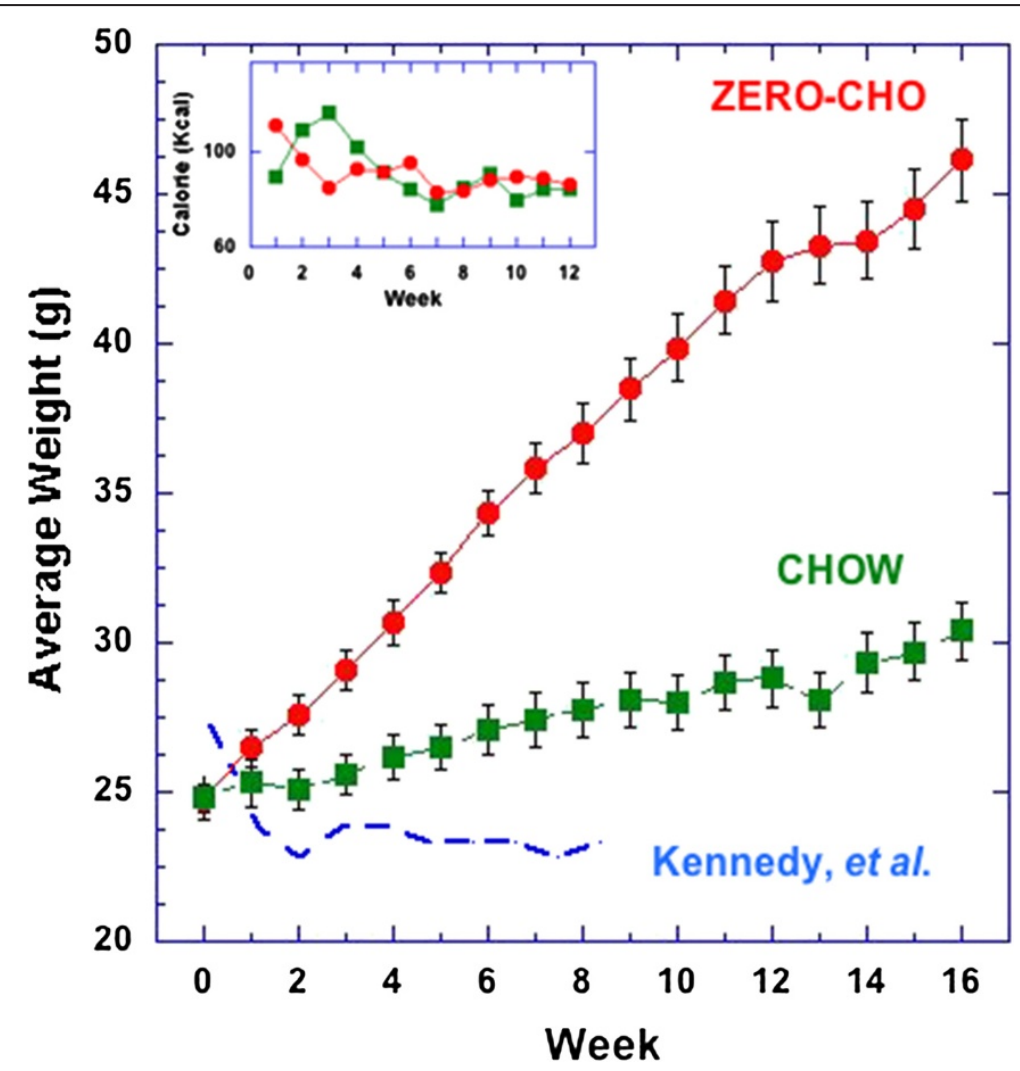

Figure 1 Average weight as a function of time on the indicated diet. Body weight and calorie intake (Inset) in male C57BI/6 mice during 16week trial period from diet groups: Chow group (green), Zero-CHO group (red). Values are mean \pm standard error. The blue dashed line shows body weights of the mice on a ketogenic diet (\% energy ratio of CHO:fat:protein =0:95:5) in the experiment reported by Kennedy that gained less weight than chow-fed mice and whose body weights were similar to calorie restricted (CR) mice that had consumed $65 \%$ of their average chow intake [2]. Statistical differences among the means were determined by one-way ANOVA for calorie intake $(P=0.38)$ and two-way ANOVA for body weight $\left(P_{<} 0.0001\right)$. 


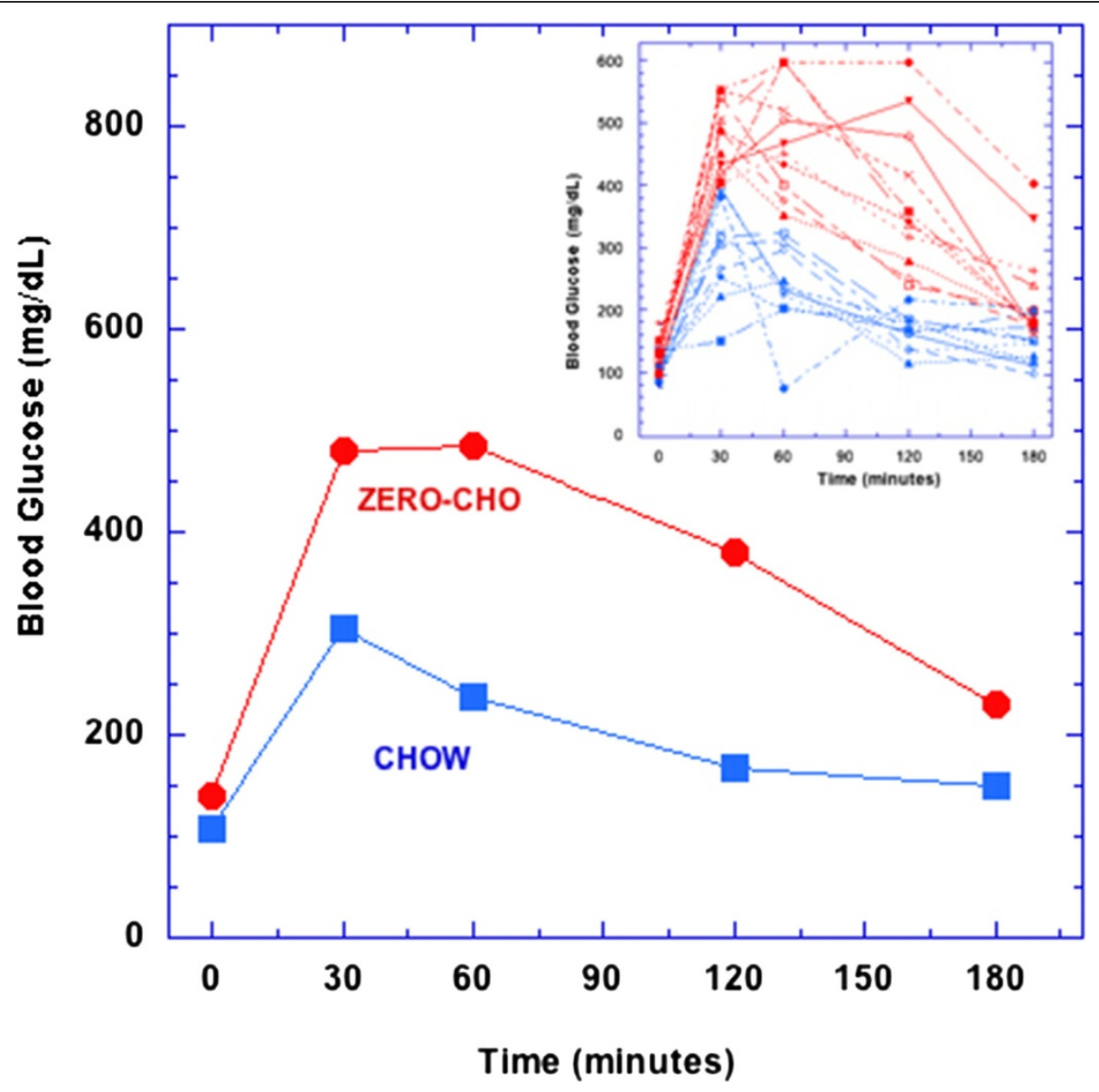

Figure 2 Glucose tolerance tests on male C57BI/6 mice fed Zero-CHO and standard Chow diets. Glucose tolerance tests were administered at week 12 of the diet trial. Blood glucose concentrations are shown at 0 min, $30 \mathrm{~min}, 60 \mathrm{~min}$, and 180 min time points: Chow group (blue), Zero-CHO group (red). Statistical differences among the means were determined using unpaired Student t-Test at each time point $(\mathrm{P}<0.0009)$. The inset to the figure shows that every animal in the zero- $\mathrm{CHO}$ group showed decreased glucose clearance.

blood leptin levels than any of the Chow fed mice (Figure 3).

\section{Discussion}

Because of the access to intracellular downstream signaling pathways, animal models provide biological information that is not generally accessible in human. The major caveat in the use of animal models is obviously that different animals have different metabolic responses. This is especially true in diet where humans are omnivores and have substantial flexibility in response to changing macronutrient composition. The "natural" diet of the mouse is dependent on strain but is generally high in carbohydrate and normal is probably operationally defined as laboratory chow. In the context of public health, one must be circumspect in generalizing from the effects in rodents where high-fat diets have an effect that appears to be far less sensitive to carbohydrates than that seen in humans. In particular, low fat recommendations continue to fail in large trials while low carbohydrate diets, even if high in fat, are more effective in isocaloric comparisons for however long they are compared.

Remarkable in the current study is the non-linear caloric response. The mice in this study showed a substantially greater increase in fat per calorie consumed than predicted by the standard "calorie-is-a-calorie" idea frequently invoked in nutrition. This has been reported previously in the literature in $\mathrm{C} 57 \mathrm{Bl} / 6$ mice on high-fat diets [15]. This is in distinction to the effect seen in humans where it is frequently found that, on lowcarbohydrate diets less fat is gained per calorie, referred to popularly as a "metabolic advantage [16]," that is, the controlling variable is carbohydrate rather than fat. While such non-linear energy efficiency was once claimed to violate laws of thermodynamics, theoretical analysis shows no contradiction from physical law and there are now numerous examples in humans and animal models [12,17]. Animal models of the type studied here make it clear that energy balance is not as assumed. 


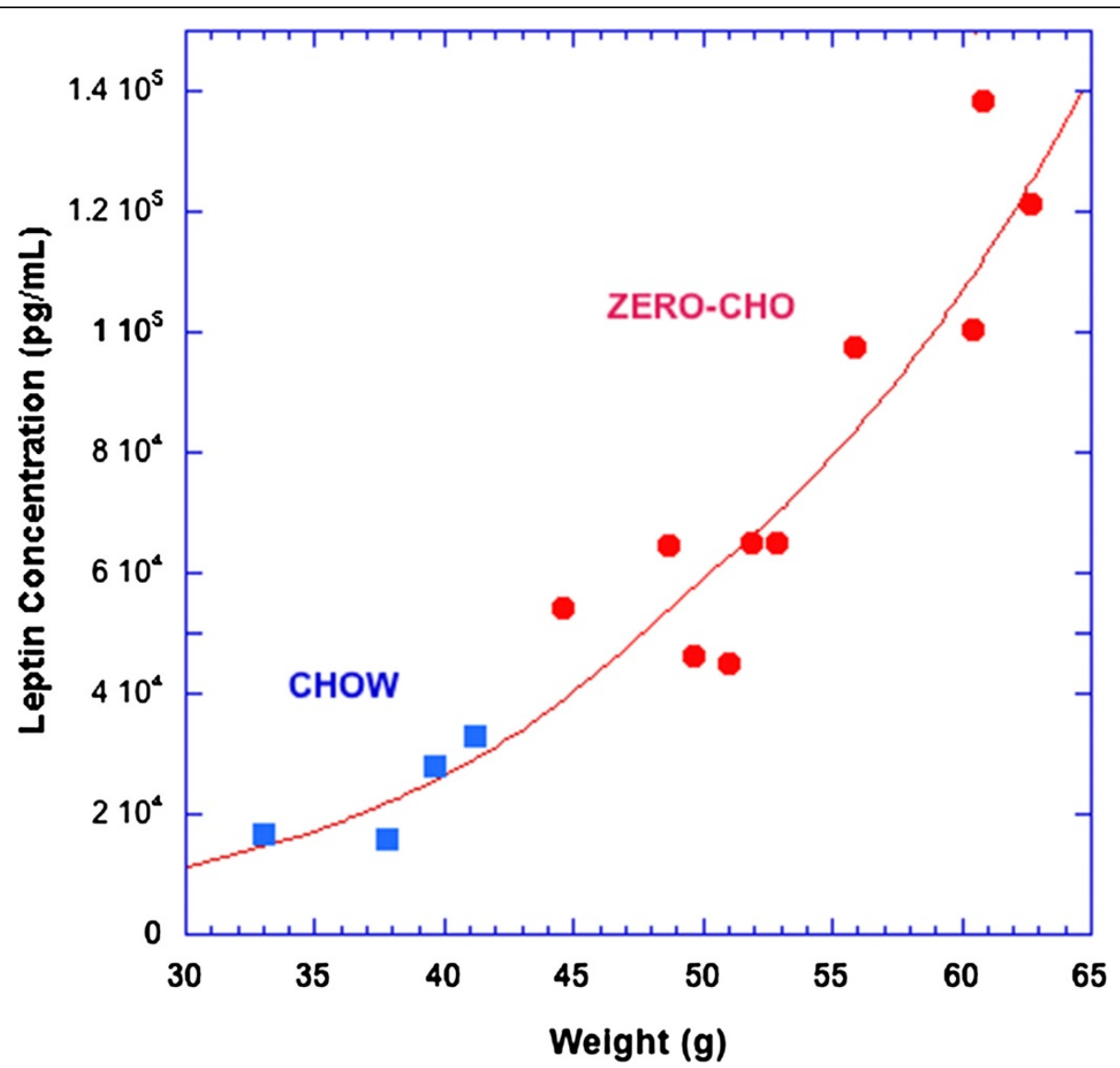

Figure 3 Correlation of blood leptin level and body weight in male C57BI/6 mice. Individual serum leptin concentration of Zero-CHO fed mice (red; $n=10$, at 55-week) and Chow fed mice (blue; $n=4$, at 57-week). Line represents exponential fit to the plotted points.

The fact that the inefficiency in humans depends on the level of carbohydrate rather than on fat as seen here in mice emphasizes the need to attend to differences in species.

Differential effect of macronutrients, in this case, saturated vs. unsaturated fatty acids was shown by Wen, et al.. [1] who found that the saturated fatty acid palmitate, but not oleate, induced activation of the NLRP3-ASC inflammasome, raising caspase-1, IL-1b and IL-18 production and this impaired insulin signaling in several tissues in culture, reducing glucose tolerance and insulin sensitivity similar to results reported here. However, in humans, Forsythe, et al. showed that compared to the response to a low fat diet (LFD) (\% $\mathrm{CHO}$ :fat:protein $=56: 24: 20)$ a low-carbohydrate, high-fat diet (\% CHO:fat:protein =12:59:28) with three times the amount of saturated fat as the LFD led to an increased proportion of serum total n-6 PUFA, mainly attributed to a marked increase in arachidonate (20:4n-6). The n-6/n-3 and arachidonic/eicosapentaenoic acid ratio also increased sharply. Both diets significantly decreased the concentration of several serum inflammatory markers, but there was an overall greater anti-inflammatory effect associated with the very low carbohydrate ketogenic diet, as evidenced by greater decreases in TNF-alpha, and numerous other markers. Increased 20:4n-6 and the ratios of $20: 4 n-6 / 20: 5 n-3$ and $n-6 / n-3$ are commonly viewed as pro-inflammatory but, unexpectedly, were consistently inversely associated with responses in inflammatory proteins $[18,19]$.

\section{Conclusions}

At least in the widely used $\mathrm{C} 57 \mathrm{Bl} / 6$ mouse, high-fat feeding, even in the absence of dietary carbohydrate, leads to obesity and an associated increase in leptin levels as well as distinct insulin resistance. This is in distinction to the results of Kennedy, et al. [14] whose ketogenic diet in $\mathrm{C} 57 \mathrm{Bl} / 6$ mice more closely resembled the beneficial state found in humans on carbohydraterestricted diets. The likely explanation is that that diet was protein-deficient and the mice were not in a normal metabolic state. In the end, the great power of modern molecular biology in rodent models may provide more evidence as to the mechanisms by which humans are different from rodents in the response to diet. 


\section{Competing interest}

The authors declare that they have no competing interests.

\section{Authors' contribution}

SB designed and carried out the experimental protocol. Both authors conceived the experiment, analyzed the data and wrote the manuscript. Both authors read and approved the final manuscript.

\section{Acknowledgments}

This work was supported in part by funds from the Research Foundation of the State University of New York.

Received: 23 April 2012 Accepted: 20 July 2012

Published: 28 July 2012

\section{References}

1. Wen H, Gris D, Lei Y, Jha S, Zhang L, Huang MT, Brickey WJ, Ting JP: Fatty acid-induced NLRP3-ASC inflammasome activation interferes with insulin signaling. Nat Immunol 2011, 12(5):408-415.

2. Ahren B: Plasma leptin and insulin in $\mathrm{C} 57 \mathrm{BI} / 6 \mathrm{~J}$ mice on a high-fat diet: relation to subsequent changes in body weight. Acta Physio/ Scand 1999, 165(2):233-240.

3. Ahren B, Sauerberg $P$, Thomsen C: Increased insulin secretion and normalization of glucose tolerance by cholinergic agonism in high fatfed mice. Am J Physiol 1999, 277(1 Pt 1):E93-E102.

4. Chan MY, Zhao Y, Heng CK: Sequential responses to high-fat and highcalorie feeding in an obese mouse model. Obesity (Silver Spring) 2008, 16(5):972-978

5. Feinman RD: Fad diets in the treatment of diabetes. Curr Diab Rep 2011, 11(2):128-135

6. Feinman RD, Volek JS: Carbohydrate restriction as the default treatment for type 2 diabetes and metabolic syndrome. Scand Cardiovasc J 2008, 42(4):256-263.

7. Feinman RD, Volek JS, Westman E: Dietary Carbohydrate Restriction in the Treatment of Diabetes and Metabolic Syndrome. Clinical Nutrition Insight 2008, 34(12):1-5.

8. Karam J, Nessim F, McFarlane S, Feinman R: Carbohydrate Restriction and Cardiovascular Risk. Current Cardiovascular Risk Reports 2008, 2(2):88-94.

9. Volek JS, Feinman RD: Carbohydrate restriction improves the features of Metabolic Syndrome. Metabolic Syndrome may be defined by the response to carbohydrate restriction. Nutr Metab (Lond) 2005, 2:31.

10. Volek JS, Fernandez ML, Feinman RD, Phinney SD: Dietary carbohydrate restriction induces a unique metabolic state positively affecting atherogenic dyslipidemia, fatty acid partitioning, and metabolic syndrome. Prog Lipid Res 2008, 47(5):307-318.

11. Westman EC, Feinman RD, Mavropoulos JC, Vernon MC, Volek JS, Wortman JA, Yancy WS, Phinney SD: Low-carbohydrate nutrition and metabolism. Am J Clin Nutr 2007, 86(2):276-284.

12. Feinman RD, Fine EJ: Nonequilibrium thermodynamics and energy efficiency in weight loss diets. Theor Biol Med Model 2007, 4:27.

13. Forsythe CE, Phinney SD, Feinman RD, Volk BM, Freidenreich D, Quann E, Ballard K, Puglisi MJ, Maresh CM, Kraemer WJ, et al: Limited effect of dietary saturated fat on plasma saturated fat in the context of a low carbohydrate diet. Lipids 2010, 45(10):947-962.

14. Kennedy AR, Pissios P, Otu HH, Xue B, Asakura K, Furukawa N, Marino FE, Liu FF, Kahn BB, Libermann TA, et al: A High Fat, Ketogenic Diet, Induces a Unique Metabolic State in Mice. Am J Physiol Endocrinol Metab 2007, 292(6):E1724-1739.

15. Ahren B, Winzell MS, Pacini G: The augmenting effect on insulin secretion by oral versus intravenous glucose is exaggerated by high-fat diet in mice. J Endocrinol 2008, 197(1):181-187.

16. Atkins RC: Dr. Atkins' New Diet Revolution. New York: Avon Books; 2002.

17. Feinman RD, Fine EJ: "A Calorie is a calorie" violates the second law of thermodynamics. Nutr J 2004, 3(9).

18. Forsythe CE, Phinney SD, Fernandez ML, Quann EE, Wood RJ, Bibus DM, Kraemer WJ, Feinman RD, Volek JS: Comparison of low fat and low carbohydrate diets on circulating Fatty Acid composition and markers of inflammation. Lipids 2008, 43(1):65-77.
19. Volek JS, Phinney SD, Forsythe CE, Quann EE, Wood RJ, Puglisi MJ, Kraemer WJ, Bibus DM, Fernandez ML, Feinman RD: Carbohydrate Restriction has a More Favorable Impact on the Metabolic Syndrome than a Low Fat Diet. Lipids 2009, 44(4):297-309.

doi:10.1186/1743-7075-9-69

Cite this article as: Borghjid and Feinman: Response of C57BI/6 mice to a carbohydrate-free diet. Nutrition \& Metabolism 2012 9:69.

\section{Submit your next manuscript to BioMed Central and take full advantage of:}

- Convenient online submission

- Thorough peer review

- No space constraints or color figure charges

- Immediate publication on acceptance

- Inclusion in PubMed, CAS, Scopus and Google Scholar

- Research which is freely available for redistribution

Submit your manuscript at www.biomedcentral.com/submit 